\title{
AN INTEGRATED APPROACH TOWARDS REVENUE MANAGEMENT
}

\section{Forthcoming in the Journal of Revenue \& Pricing Management}

\author{
Irene $\mathrm{C} \mathrm{L} \mathrm{Ng}{ }^{1}$ \\ Roger Maull, ${ }^{2}$ \\ Philip Godsiff ${ }^{3}$
}

\footnotetext{
${ }^{1}$ Irene $\mathrm{C} \mathrm{L} \mathrm{Ng}$ is an Associate Professor of Marketing at the School of Business and Economics, University of Exeter, Streatham Court, Rennes Drive, Exeter EX4 4PU, United Kingdom Tel: +44 (0) 1392 263250, Fax: +44 (0) 1392 263242, Email: Irene.ng@exeter.ac.uk

${ }^{2}$ Roger Maull is a Professor of Management Systems at the School of Business and Economics, University of Exeter, Streatham Court, Rennes Drive, Exeter EX4 4PU, United Kingdom Tel: +44 (0) 1392 263213, Fax: +44 (0) 1392 263242, Email: r.s.maull@exeter.ac.uk

${ }^{3}$ Philip Godsiff is a Doctoral Candidate at the School of Business and Economics, University of Exeter, Streatham Court, Rennes Drive, Exeter EX4 4PU, United Kingdom Tel: +44 (0) 1392 263213, Fax: +44 (0) 1392 263242, Email: phil.godsiff@exeter.ac.uk
} 


\title{
AN INTEGRATED APPROACH TOWARDS REVENUE MANAGEMENT
}

\begin{abstract}
This paper argues that advanced demand exhibit three characteristics that of being probabilistic, stochastic and deterministic. Deterministic demand results in revenue management practices being cross-functional. The paper proposes a new revenue management system that integrates four decision sets of the firm: the value set, the segmentation set, the sensitivity set and the forecasting set. An integrated revenue management system also links the concept of capacity to the attributes promised by the firm to the customer. The paper then proposes that service firms that do not sell 'unitized' services such as seats or rooms has to define and capture its amorphous capacity and through capacity limitation, create advanced demand and practice strategic revenue management.
\end{abstract}

Keywords: Capacity, Advanced Demand, Value, Segmentation, Sensitivity, Forecasting 


\section{AN INTEGRATED APPROACH TOWARDS REVENUE MANAGEMENT}

Revenue management is the maximization of revenue by "selling the right seats to the right customer at the right time". (American Airlines 1987, as cited in Weatherford and Bodily 1992, pg. 832) This definition was subsequently modified to include "and at the right price" (i.e. to add the option of multiple prices) (Kimes 1989, Pak and Piersma 2002, Kimes and Thompson 2004, Yeoman et al. 1999, Upchurch et al. 2002).

Over the past 30 years, revenue management research has evolved in scope. Beginning in the seventies, Rothstein [1971, 1974] and Littlewood [1972], investigated practices of revenue management in airlines and hotels. With the deregulaton of the the airline industry in 1978, more research followed, leading to the seminal papers of Belobaba [1987a, b, 1989] that propelled revenue management into mainstream operations research (OR). At that point in time however, the understanding of revenue management was largely on a computational and operational level, with literature dominated by operations researchers [Desiraju and Shugan, 1999]. Hence, the scope of revenue management was limited to capacity planning and allocation, for a given set of prices'. Gradually, it became evident that revenue management research should factor in the pricing policies of firms, and also make demand or consumer behavior endogenous to revenue management [Fleischmann et al., 2004; Ng, 2007]. It also became clear that the practice of revenue management was applicable to other service firms besides airlines and hotels, which led to research papers on revenue management in industries such as car rental and Internet service providers (e.g. Carroll and Grimes, 1995; Nair and Bapna, 2001).

With the advent of the Internet and other advances in technology, revenue management also became increasingly complex [Elmaghraby and Keskinocak, 2003]. Great leaps in computation power allowed for more complex optimizing algorithms to emerge, while the Internet made it possible to constantly collect the data necessary for the generation of better forecasts to aid firms in both capacity allocation and pricing. This gave rise to the possibility of instantaneous decision making, enabling revenue management systems to be more efficient and responsive. Also, in the past, demand data was far more difficult to obtain and less systematic to process and as a result, supply-driven revenue management was a natural research orientation. However, with the Internet becoming ubiquitous, the information asymmetry between supply and demand reduced. With more demand data being made available, it became necessary to have a balanced view of revenue management, leading to increasing research possibilities in this area.

As the scope of revenue management expanded beyond being an optimization issue to include pricing and demand behavior, revenue management became multi-disciplinary in nature, with pricing/demand and consumer research as one stream of focus, and capacity allocation, booking policies and related supply-driven issues as the other [Kimes, 2003]. 
Researchers soon realized that the issue of revenue management could not be adequately addressed within just one discipline. While pricing and demand behavior were important, so was capacity allocation and planning, and all these areas needed to be brought into revenue management. Despite the need for integration however, few attempted it [Fleischmann et al., 2004; Kimes and Wirtz, 2002, 2003]. This is also reflected in practice; in commenting on the airline industry, Cary [2004: 202] claimed:

\begin{abstract}
...Pricing and revenue management - function so differently within the US airline industry. Pricing is almost entirely outwardly focused on the actions and reactions of competitors. Revenue management is almost entirely inwardly focused on the patterns and trends in historical demand data. Both are in need of adjustment.
\end{abstract}

In attempting to integrate pricing research with capacity allocations, one of the main challenges faced is that OR-based revenue management often assumed demand to be stochastic or probabilistic, whilst pricing research tend to model demand as deterministic. Marketing researchers are keen to understand if a theoretical structure exists that could explain how demand is shaped or why it would follow a particular pattern across time. Some research studies have attempted to shed some light on the behavior of the advanced buyer. The literature is scant, dominated by marketing literature, and not commonly brought into traditional revenue management research. For example, Desiraju and Shugan [1999] evaluated strategic pricing in advanced selling and found that yield management strategies such as discounting, overbooking and limiting early sales work best when price-insensitive customers buy later than price-sensitive customers. Shugan and Xie [2000] demonstrated that the state dependency of service utility caused buyers to be uncertain in advance and certain at consumption time, while sellers remain uncertain of the buyer's state at consumption time due to information asymmetry. They suggest that this informational disadvantage can be overcome by advance selling, which then becomes a strategy to increase profit. Xie and Shugan [2001] went on to study when advanced selling improves profits and how advanced prices should be set. Their areas of investigation include the optimality of advanced selling, investigating selling in a variety of situations, buyer risk aversion, second period arrivals, limited capacity, yield management and other advanced selling issues.

On the other hand, Png [1989] showed that costless reservations in advance is a profitable pricing strategy, as it induces truth revelation on the type of valuation that the consumer has for the service (which is private information). In another paper, Png [1991] weighed the strategy of charging a lower price for advanced sales and attaching a price premium at consumption date, against one of charging a premium at advanced sale and promising a refund should consumption prices be lower than what was originally purchased.

While these models aim to capture primitive advanced demand behavior, little effort has been made to integrate them into revenue management research. 
As these models capture individual consumer behavior (or homogeneous consumer segments), it was difficult to see how that could be aggregated and applied to revenue management that mostly dealt with stochastic heterogeneous market demand. Lee and $\mathrm{Ng}$ [2001] attempted to model the demand phenomenon at a market level but it was unclear why their demand function was shaped the way it was.

\section{Advanced Demand could be Deterministic}

One way of integrating behavioral aspects of demand into revenue management literature is to recognize that advanced demand could be deterministic. Most revenue management literature model demand as stochastic or probabilistic. The stochastic (random) aspect of advanced demand exists because consumers 'arrive' at random times before consumption, and it is a challenge to predict when such arrivals happen during the advanced selling period. The probabilistic aspect of advanced demand arises where even if buyers arrive at a particular time, they may decide to buy, not buy, or wait till closer to consumption time due to perceptual factors and the firm's selling policies. Yet, there is also a deterministic component in advanced demand, where volume and prices purchased at could be determined by the firm's policy.

\section{$<$ Insert Figure 1 here $>$}

Shugan and Xie (2000) provided the first insights to the antecedents to advanced demand behavior that could be deterministic. Since most services are produced and consumed simultaneously, the consumer can only buy in advance and consume later without the chance to store. Similarly, the firm can only sell in advance and produce later. This is an important point. According to conventional economic wisdom, we buy only when the utility we attach to consuming the product outweighs the price we are supposed to pay for it. However, normative economics and marketing literature often implicitly assume that utility is received at the time of purchase. A separation of time between purchase and consumption however, implies that the consumer truly obtains utility not at the time of purchase, but at the point of consumption (c.f. Shugan and Xie, 2000).

This is significant because when purchase and consumption are separate, there is a probability that a buyer who has purchased may not be able to consume i.e. the utility becomes state-dependent (c.f. Karni, 1983; Fishburn, 1974; Cook and Graham, 1977). For instance, a buyer purchases a movie ticket an hour before the movie. When the time of the movie comes however, s/he is unable to watch it because s/he has fallen ill. $\mathrm{Ng}(2007,2008)$ described the risks faced at the point of purchase as a trade-off between valuation risk (the risk of not valuing the service at the same level upon consumption if the buyer buys too early) and acquisition risk (the risk of not being able to acquire the service if the buyer buys too late). Given this trade-off, $\mathrm{Ng}$ proposed that a market would exist for selling the service far in advance to buyers looking to ensure the availability of the service. This is regardless of whether or not the seller is willing to sell to this market. Similarly, there would also be a market for selling at (close to) consumption time for buyers who would like to ensure that they are able to consume.

With the trade-off between acquisition risk (which drive buyers' willingness to buy further in advance) and valuation risk (which drive buyers' willingness to buy 
closer to consumption), the demand for services is not merely one demand function but continuous demand functions distributed across the advanced selling period (assuming the advanced selling period exists). Hence, firms face uncertainty both in the demand distribution across time and the elasticity of demand for the service at each point in time during the selling period. Yet, this demand may be deterministic since the risks faced by the buyers could be ameliorated by the firm's service policy e.g. allowing flexibility on the time of consumption of the service. Similarly, the firm's pricing policy also has an effect on advanced demand e.g. if the advanced price is low, more buyers may buy in advance. Consequently, there is some degree of cross-time dependence between advanced and spot demand, lending to the deterministic aspect of demand.

One final point lends further weight to the argument that advanced demand could be deterministic i.e. the firm's capability to re-sell advanced capacity. The consumption and production of services are inseparable, hence buyers often have to present themselves (or at least, the item that requires the service) at the time of consumption. So, even if the purchase is made in advance, the buyer still has to 'show up' to consume. As such, there will exist a fraction of advanced buyers who may not be able to consume the service during that specified time, particularly so when the purchase is conditional upon a particular consumption time. Various revenue management literatures have commonly acknowledged this thought, and attempts have been made to structure various reservation policies to minimize the impact of the cancellation and 'no-show' concept of advanced selling. (e.g. Alstrup et al., 1986; and Belobaba 1989; Hersh and Ladany, 1978; Subramanian et al., 1999; Toh, 1985). Until Ng (2007), academic literature have not discussed the existence of a non-zero probability of non-consumption by advanced buyers which in turn provides a service firm with a unique opportunity not presented to goods firm i.e. the ability to re-sell at spot, the capacity that was already sold in advance. This re-selling capability may then translate into additional profit for the firm, be it from the additional spot sales, or from the advanced overselling of the firm's capacity. For example, IT support services are usually oversold at a cheap rate to buyers in advance, with the expectation that non-consumption may be high, especially if the IT equipment is reliable and functions well. This allows the IT support firm to market to other clients who may not have purchased the advanced package but are prepared to pay higher spot prices for its services. Similarly, it may be a low fraction of the market that actually requires breakdown services, hence breakdown service firms would oversell their capacity in advance (albeit at a very low price) through the Automobile Association (AA), often in the form of insurance. They are also able to re-sell their services at spot, at a higher price to those who did not subscribe to the insurance.

Firms can re-sell relinquished capacity of advanced buyers in a few ways. First, the firm can re-sell to spot demand, if such demand exists. Second, the firm could have inventoried advanced demand and re-sell the capacity to those on the 'waiting list' at spot time when it becomes apparent that some capacity have been relinquished. Finally, the firm could try to forecast the proportion of nonconsuming advanced buyers and oversell that proportion in advance to other advanced buyers, an option commonly referred to in revenue management as 
overbooking (e.g. Karaesmen and van Ryzin, 2004). The capacity that firms can re-sell at consumption time depends on the firm's sales policy e.g. providing refunds for no-shows (because it could re-sell at spot). In general, such a strategy would have a huge impact on overbooking, no-shows and profits. This implies that no-shows may not be as random, nor overbooking the only solution, when viewed against the broader context of the phenomenon. Deterministic demand suggests that buying behavior can be controlled and indeed influenced by the firm's pricing policy with strategic demand shifting mechanisms such as refunds etc.

With better technologies and increased connectivity between sellers and buyers, firms are endeavoring to reduce the uncertain nature of advanced demand through forecasting and the development of dynamic pricing models would need to include the three characteristics of advanced demand; stochastic, probabilistic, and deterministic.

\section{Integrated Approach towards Revenue Management}

If advanced demand is partially deterministic as proposed in the previous section, it is therefore endogenous to the firm and may be influenced by many of the decisions made by the firm such as price, quality, product/service attributes. This implies that the research and practice revenue management now has to consider other elements that would involve other disciplines and functional groups within the firm respectively. This seems to be a natural evolution of RM research as the use of revenue management strategies begins to gain popularity across various other high fixed cost services. The practice and research of RM is under pressure to broaden its focus, and with it, to understand the linkages between the various disciplines. Today, revenue management needs to embrace a new era where operations management, operations research, marketing, economics and technology all play important roles. Revenue management is challenged to organize the end-to-end solutions, from the firm's supply and capacity to the buyers' value and demand for the service.

The new revenue management system comprises four decision sets and various components, as represented in Figure 2. From the demand end, buyers pay a price according to the benefits obtained through the attributes of the service. This value set requires the firm to select the most appropriate attributes that would provide the highest possible benefit to buyers. Conversely, the benefits buyers require can help determine the type of attributes to be chosen by the firm.

In deciding on the types of benefits to provide however, firms have to consider those that would appeal to different market segments, as this enables it to price discriminate for each segment i.e. the segmentation set has an influence on the value set. Hence, it's not merely about which attributes that provide what types of benefits, but how the benefits are able to help the firm separate the market into the various segments $(\mathrm{Ng}, 2006)$.

For instance, most airline customers are segmented according to first class, business class and economy class passengers. Each market segment value different benefits; economy class passengers seek the best value for money., while business class passengers would value comfort and personalised 
service, and first class passengers value the additional benefit of exclusivity. As the latter two buyer segments are willing to pay more for the additional benefits they value, airlines are able to charge different prices for the three different segments.

Yet, some segments do not result in the service being priced higher but instead, provide higher demand. Consequently, whatever the prices charged must be dependent on how many buyers would show up for each price point. Hence, the sensitivity set involves the price/quantity set which determines how much the firm should price to obtain its required quantity. In the above example on airlines, the different prices set for the different market segments result in different purchase volume. The highest volume would be from the advanced fare economy class, where high demand (not high price) provides the firm with higher revenue. Conversely, the firm obtains higher revenue from the higher prices for first class tickets.

Finally, even if the price/volume relationship is known, the practice of selling the service in advance is in itself, uncertain. Hence, the forecasting set involves how much of the firm's capacity should be filled with the different quantity/price from different segments based on the forecasted distribution of demand. Using the above example of the airlines, the firm might forecast more last minute demand for economy class (for which it can charge a higher fare), and therefore might not sell all its capacity to advanced buyers.

\section{$<$ Insert Figure 2 here $>$}

The integrated revenue management system captures the interdependence of these four decision sets in a service. By taking on an integrated approach, more strategic tools can be developed in improve revenues, allowing for creativity and innovation in pricing approaches (e.g. $\mathrm{Ng}$ and Yip, 2007). However, the interdependence does not end here, as the following discussion will show.

\section{Identifying Capacity and Identifying opportunities for Revenue Management}

Across industries, services differ and although they share many similar characteristics, no concerted attempt has been made to understand how capacity is constituted in different service firms. Yet, as presented in Figure 2, capacity is an integral part of pricing and revenue management for services. To practice revenue management in an integrated manner, a service firm must first define what 'capacity' is.

Brown et. al. define capacity as the potential output of a system that can be produced in a specified time, determined by the size, scale and configuration of the system's transformation inputs (Brown, et. al. 2004). This definition has a number of useful components; it limits the time period, focuses on potential as opposed to actual output and discusses the concept of a system and the transformation of inputs into outputs. However, this definition makes no mention of the quality of the outputs; capacity that can produce large volumes of output that meets the customer requirement is very different from capacity that does not. We venture a definition based on Brown et. al. that capacity is the potential ability 
of a system to produce output of a given quality, according to attributes promised to customers, over a given time period. The system by definition includes transformations (see for example Katz and Kahn, 1966) and includes all the factors of production. The potential capacity is constrained by the way in which these factors of production are able to operate and has to deliver according to the attributes promised to customers.

A helpful concept for identifying and analysing capacity is the Theory of Constraints (TOC) (Goldratt, 1990). TOC is rooted firmly within the systems paradigm and was developed by Goldratt in the 1980s. Initially, it was limited to application in manufacturing through such software as Optimised Production Technology (OPT). However, it has subsequently become clear that identifying bottlenecks (constraints) had application in many public and service sector organisations as well as manufacturing.

TOC is based on the premise that an organisation will always have one limiting condition that prevents the organisation meeting its goal. This limiting condition is the constraint. Central to TOC is the logic that the output of the constraint is the output of the entire system. Take for example the insurance claims process depicted in Figure 3. Customers contact the call centre to make a claim. The claim documentation is handled by the claims department who pass on the claim to the assessor who makes adjudication on the claim. Once agreed the necessary documentation for payment is set up and finally payment is made. In this case daily limits for each stage in the process are shown. The constraint (bottleneck) is clearly the assessment step where expert knowledge and highly trained staff are required.

$<$ Insert Figure 3 here $>$

Handling calls and processing claims have greater daily capacity than assessment. However, the logic of TOC is that working faster than the constraint, upstream of the constraint, means inventory/queues build in front of the constraint. If 80 claims a day can be input into the system yet only 20 can be assessed, obviously 60 per day will build up as 'work in progress'.

Downstream of the constraint, it is not possible to carry out the set up and to make payments faster than assessment as these activities are limited by the bottleneck. It may be theoretically possible to set up the payment for 100 claims per day but the actual capacity is limited by the 20 per day processed by the assessors. The constraint, i.e. the bottleneck, helps us to identify the capacity. This concept clearly has widespread application in services. If a firm could actually charge different prices for each claim processed, its capacity ('inventory') is only 20 per day and the allocation of how much of such capacity is 'sold' at the different prices is a revenue management challenge.

Identifying capacity in a system where the constraint is physical is relatively straightforward. For example, in a cinema, the bottleneck is the number of seats and the same is true of an airline and a sports stadium. In manufacturing, the constraint is also often easily identified because the observer can see Work In Progress (WIP) building in front of the bottleneck.

However in other service systems such as banking or news provision, the constraint is much harder to define and in some cases this makes the capacity 
variable. Take, for example an organisation that takes multiple data inputs from which it produces reports for the media. There is a wide variety of data inputs that need to be consolidated before assessment. The data for the activity "consolidate data" is shown below in Figure 4. This data set is taken from a large sample over 4 months. We can see that the consolidation times vary between a few seconds and over 28 minutes with the median being very different from the mean.

\section{$<$ Insert Figure 4>}

Identifying the capacity of this (crucial) step in the process depends on how long the activity takes, which in turn depends on the complexities of the input. In reality, this activity is the constraint although admittedly, it could be other activities in the process transformation as it depends on the nature of the input.

The above illustrates that processes should not be excluded when considering how the capacity of the firm should be defined. In other words, when the supply of a service firm's capacity is linked to the benefits delivered to the buyer in an integrated approach, the delivery of the service and the firm's capacity to deliver it depends on what attributes have been promised (i.e. the dashed arrow in Figure 2).

Thus, the definition of a firm's capacity may not be as simple as seats on a flight or the capacity of a lecture theatre for the delivery of an educational programme. Although the costs of delivering that capacity may already be sunk at the point of sale, and marginal costs are negligible, there is an argument for understanding how the fixed costs are spent to create the firm's service capacity which, at the other end, is defined by what the customer expects.

Defining the capacity of service firms that do not sell 'unitized' services such as seats or rooms is crucial towards being able to practice revenue management (Bitran and Caldentey, 2003). Such amorphous capacity is analogous to 'inventory' in hotels and airlines. By being able to define and capture such amorphous capacity through modularization or other techniques, different service firms could then identify what 'inventory' is for their service offering. When such inventory is defined, its limitation could create advanced demand ( $\mathrm{Ng}, 2007$ ), allowing the firm to do 'capacity' allocation for varied price levels and practice revenue management. Applying the integrated approach set out here, it also allows the firm to create different value propositions for the market (e.g. different processing times) for second-degree price discrimination.

Thus, identifying capacity is the first step towards the practice of revenue management. By the term 'revenue management', we do not mean price discrimination alone. Almost all services are able to price discriminate between different buyer segments. Revenue management requires the firm not merely to be able to price discriminate, but to be able to sell both in advance and at spot as well as inventory demand for its limited capacity. Not all services are able to do that. Understanding the firm's capacity and limiting it could create advanced demand and by creating advanced demand, the firm can then choose, in an integrated approach as suggested in this paper, to open itself to the world of many strategic revenue management practices. 


\section{Conclusion}

An integrated approach towards revenue management opens up opportunities for firms to innovate and be creative in their revenue management strategies. It also allows firms to compete through non-price components, capturing different value propositions valued by different segments. However, adopting an integrated approach implies the need for researchers to work across disciplines, and for staff of service firms to work across functions. This would pose the biggest challenge as politics and turf issues could dominate and a sense of ownership towards the challenge may be lost. Firms need to evaluate their current organizational model to achieve their pricing and revenue management objectives to meet the challenge of constant change sweeping through their industries. Top companies now ensure that their pricing policies are decided by departments that are stakeholders of the pricing decision (Bright, et. al. 2006). By ensuring that executives from across the organisation is involved in the intricacies of pricing discussions, more opportunities can be discovered and pricing and revenue management strategies could be more creative, allowing for greater revenues to be realised. 


\section{REFERENCE}

Alstrup, J., S. Boas, O. Madsen, and R. Vidal (1986) Booking Policy for Flights with Two Types of Passengers, European Journal of Operations Research, 27, 274-288;

Belobaba P.P. (1987a) Air Travel Demand and Airline Seat Inventory Management. Doctoral dissertation, Flight Transportation Laboratory, Massachusetts Institute of Technology, Cambridge, MA;

----- (1987b) Airline Yield Management: An Overview of Seat Inventory Control, Transportation. Science, 21, 63-73;

------ (1989) Application of a probabilistic decision model to airline seat inventory control, Operations Research, 37, 183-197.

Bitran, G., and Caldentey, R. (2003) An Overview of Pricing Models for Revenue Management. Manufacturing and Service Operations Management, 5(3), 203-229.

Bright, Kevin J., Dieter Kiewell, and Andrew H. Kincheloe (2006), "Pricing in a proliferating world", McKinsey Quarterly, August, web-edition, http://www.mckinseyquarterly.com/article_page.aspx?ar=1841\&L2=16\&L3=0 (accessed 2 Jan 2007)

Brown, Steve, Richard Lamming, John Bessant and Peter Jones (2004) Strategic Operations Management Butterworth-Heinemann Ltd; 2Rev Ed edition

Carroll, W. J., and Grimes, R. C. (1995) Evolutionary change in product management: Experiences in the car rental industry, Interfaces, 25 (5), 84104

Cary, D. (2004) A view from the inside, Journal of Revenue and Pricing Management, 3 (2), 200-203(4).

Cook, Phillip J., \& Graham, Daniel A. (1977). The demand for insurance and protection: The case of irreplaceable commodities. Quarterly Journal of Economics, 91 (February), 143-154.

Desiraju, R., and Shugan, Steven M. (1999) Strategic Service Pricing and Yield Management, Journal of Marketing, 63, 44-56.

*Elmaghraby, W., and Keskinocak, P. (2003) Dynamic pricing in the presence of inventory considerations: Research overview, current practices, and future directions, Management Science, 49 (10), 1287- 1309.

Fishburn, C. (1974). On the foundations of decision making under uncertainty. In M.Balch, D. McFadden, \& S. Wu (Eds.), Essays on Economic Behavior under Uncertainty..Amsterdam: North Holland Publishing Co

Fleischmann, M., J. M. Hall, and D. F. Pyke (2004) Smart Pricing, MIT Sloan Management Review, 45 (2), 9-13.

Goldratt, E.M. (1990), Theory of Constraints, North River Press, Croton-onHudson, NY.,

Hersh, M., and Ladany, S. P. (1978) Optimal Seat Allocation for Flights with One Intermediate Stop, Computers and Operations Research, 5, 31-37;

Karaesmen, I., and van Ryzin, G. (2004) Overbooking with Substitutable Inventory Classess, Operations Research, 52 (1), 83-104. 
Karni, Edi. (1983). Risk aversion for state-dependent utility functions: measurement and applications. International Economic Review. 24(3), (October), 637-647;

Katz D \& Kahn R L. The social psychology of organizations. New York: Wiley, 1966.

Kimes, S. E. (1989) Yield Management: A Tool for Capacity Constrained Service Firms, Journal Of Operations Mgmt, 8, 348-363;

(2003) Revenue Management: A Retrospective, Cornell Hotel and Restaurant Administration Quarterly, 30 (3), 14-19.

------ and Wirtz, J. (2002) Perceived fairness of demand-based pricing for restaurants, Cornell Hotel and Restaurant Administration Quarterly, 41 (1), 338;

------ and Wirtz, J. (2003) Has revenue management become acceptable? Findings from an international study on the perceived fairness of rate fences, Journal of Service Research, 6 (2), 125-135.

----- \& G. M. Thompson (2004). "Restaurant revenue management at Chevys: determining the best table mix." Decision Sciences, 35 (3), 371-392.

Lee, K. S., and Ng., I. C. L. (2001) Advanced Sale of Service Capacities: A Theoretical Analysis of The Impact of Price Sensitivity on Pricing and Capacity Allocations, Journal of Business Research, 54 (3), pp. 219-225.

Littlewood, K. (1972) Forecasting and control of passenger bookings, 1972 AGIFORS Symposia, Alliance Group of the International Federation of Operational Research Scientists, Vol. 12, 95-117

Nair S. K., and Bapna, R. (2001) An Application of Yield Management for Internet Service Providers, with Suresh Nair, Naval Research Logistics, 48 (5), 348362.

Ng, Irene C. L. (2006), "Differentiation, Self-Selection and Revenue Management", Journal of Revenue and Pricing Management, 5 (1), 2-9

(2007) "Advanced Demand and a Critical Analysis of Revenue Management", Service Industries Journal, 27(5), July, 525-548

and Nick K.T. Yip, (2007) "Revenue Management on a Gaming and Holidaying Cruise Ship: The Case of Empress Cruise Lines", Proceedings of the Tenth Quality in Services Symposium, QUIS 10, 14-17 June, Orlando, Florida

(2008) The Pricing and Revenue Management of Services: A Strategic Approach, Published By Routledge, An Imprint Of Taylor And Francis, under the Advances in Business and Management Studies, Hardback, Jul 2007

Pak, K., and Piersma, N. (2002) Overview of OR Techniques for Airline Revenue Management, Statistica Neerlandica, 56 (4), 479-495;

Png, I. P. L. (1989) Reservations: Customer Insurance in the Marketing of Capacity, Marketing Science, 8 (3), 248-264.

----- (1991) Most-Favored-Customer Protection versus Price Discrimination over Time, Journal of Political Economy, 99 (5), 1010-1028.

Rothstein, M. (1971) An Airline Overbooking Model, Transportation Science, 5, 180-192; 
----- (1974) Hotel Overbooking as a Markovian Sequential Decision Process, Decision Sciences, 5, 389-394.

Shugan, S.M., and Xie, J. (2000) Advance pricing of services and other implications of separating purchase and consumption, Journal of Service Research, 2 (3), 227-239.

Subramanian, J., Stidham Jr, S. and Lautenbacher, C. J. (1999) Airline Yield Management with Overbooking, Cancellations and No-Shows, Transportation Science, 33 (2), 147-167;

Toh, R. (1985) An Inventory Depletion Overbooking Model For the Hotel Industry, Journal of Travel Research, Spring, 24-30.

Upchurch, R. S., Ellis, T. and Seo, J. (2002) Revenue Management underpinnings: An Exploratory Review, Hospitality Management, 21, 67-83.

Weatherford, L. R., and Bodily, S. E. (1992) A Taxonomy and Research Overview of Perishable-Asset Revenue Management: Yield Management, Overbooking, and Pricing, Operations Research, 40, 831-844.

Xie, J. and Shugan, S. M. (2001) Electronic Tickets, Smart Cards and Online Prepayments: When and How to Advance Sell, Marketing Science, 20 (3), 219-243

Yeoman, I., Ingold, A. and Kimes, S. E. (1999) Yield Management: Editorial Introduction, Journal of Operational Research Society, 50, 1083-1084; 
Figure 1: The three characteristics of advanced demand

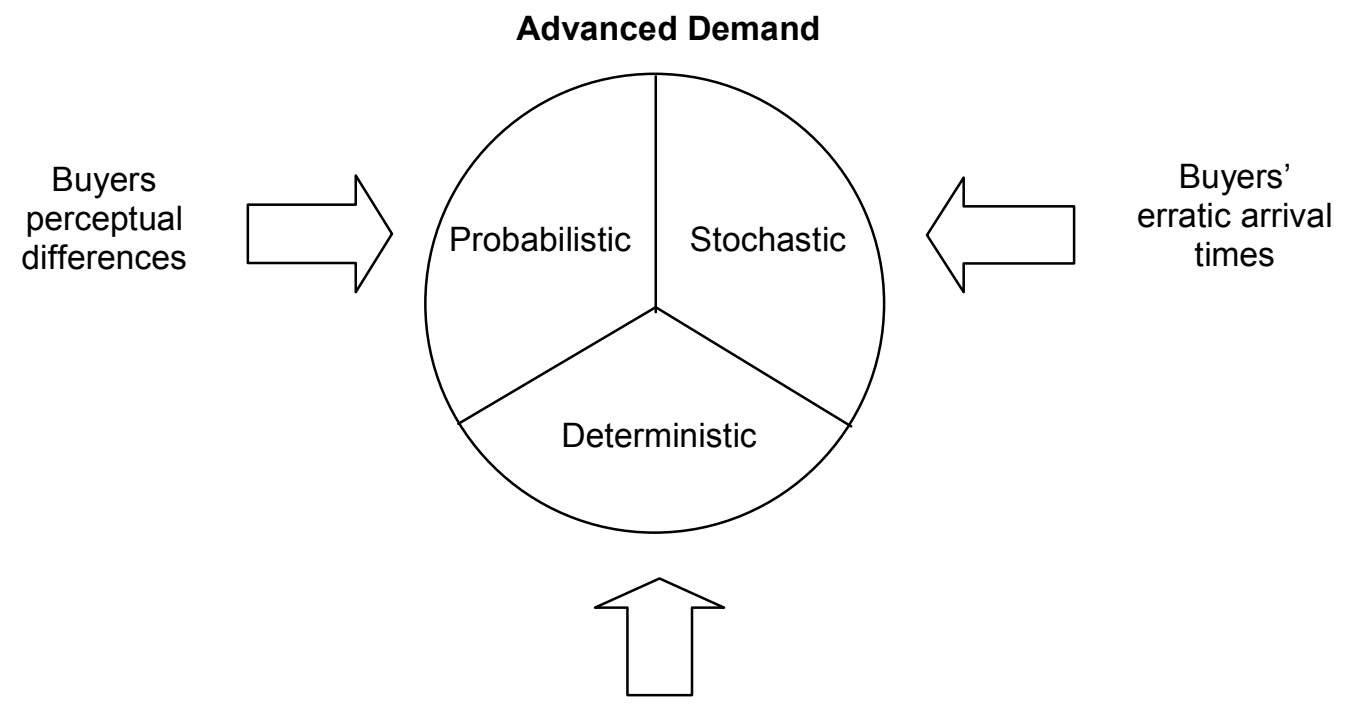

Buyers' behaviour from firm's pricing policy 
Figure 2: Interdependence of the four decision sets in revenue management

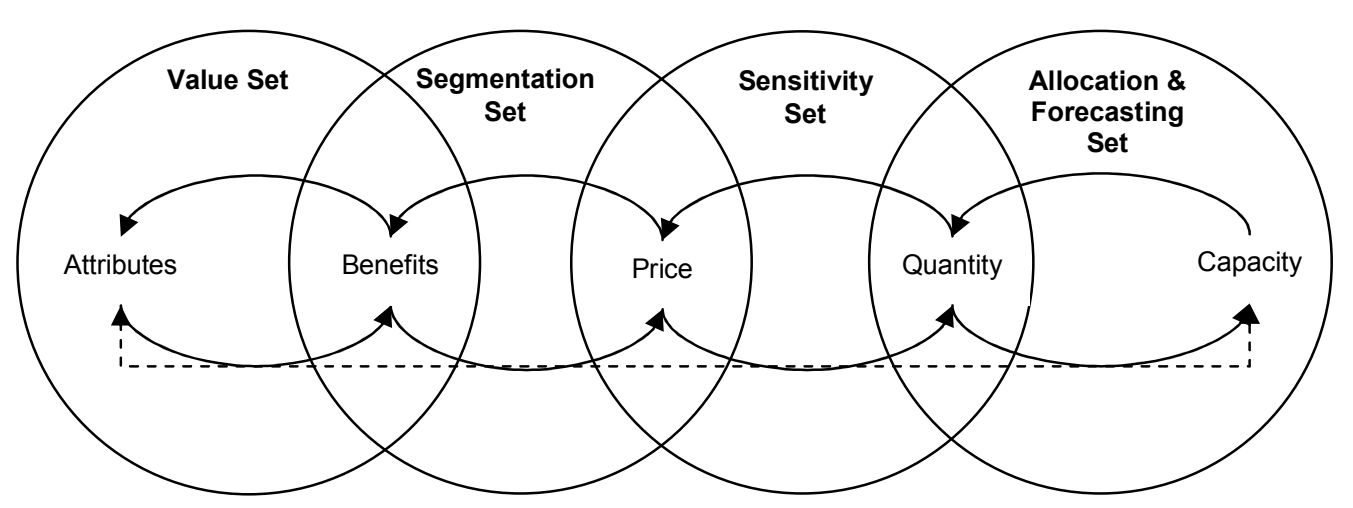


Figure 3: Claims processing

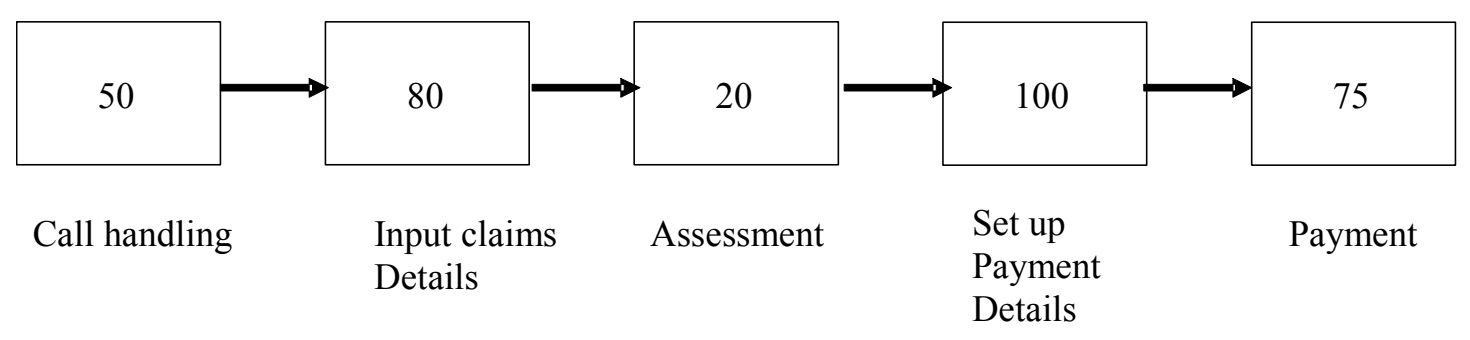


Figure 4: Processing Time

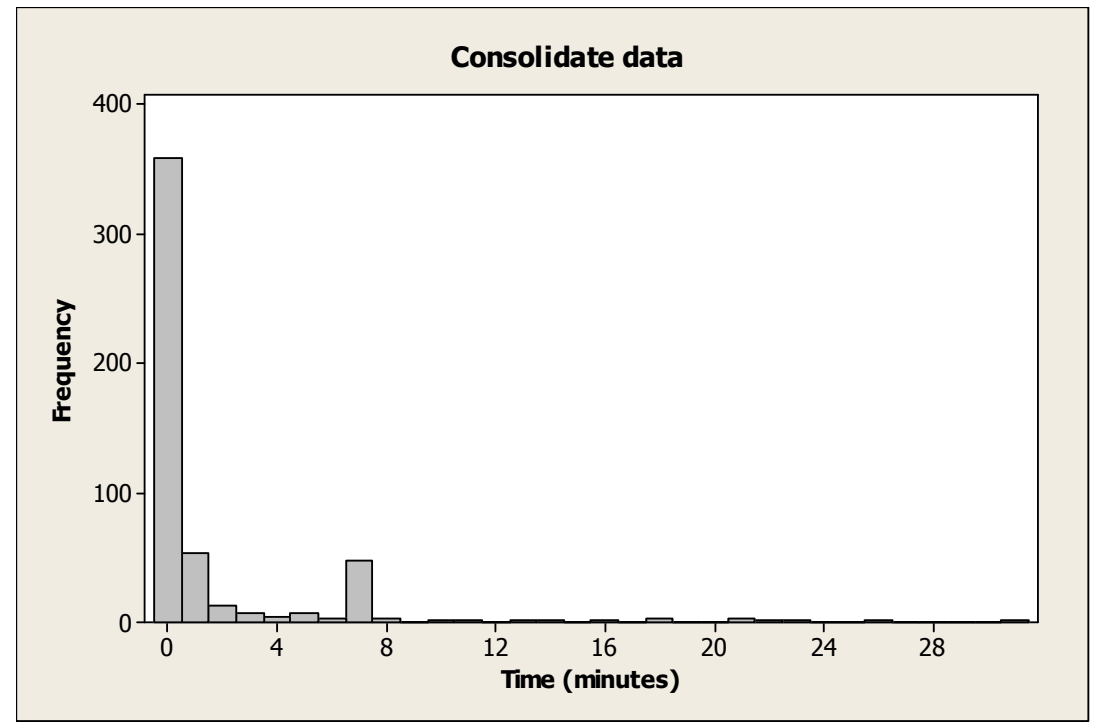

